\author{
Como citar este artigo: \\ VALENTE, Manuel Monteiro Guedes. Processo Penal, Segurança \\ e Liberdade: uma provocação. Revista Brasileira de Direito \\ Processual Penal, Porto Alegre, vol. 1, n. 1, p. 105-120, 2015. \\ http://dx.doi.org/10.22197/rbdpp.v1i1.6
}

\title{
PROCESSO PENAL, SEGURANÇA E LIBERDADE: UMA PROVOCAÇÃO
}

Manuel Monteiro Guedes Valente ${ }^{1}$

http://dx.doi.org/10.22197/rbdpp.v1i1.6

\begin{abstract}
RESUMO
O presente artigo enfoca a questão da afirmação dos direitos humanos desde a perspectiva da liberdade, segurança e justiça na construção de um Processo Penal Democrático. Isso tendo em vista a necessária preocupação do mundo jurídico quando da realidade da sociedade permeada pela incerteza dos fenômenos negativos, relacionados com modelos autoritários ou bélicos do direito penal material e processual em contraste ao modelo garantista. A discussão passa pela problemática do enfrentamento da reedificação do Direito Penal do autor, voltado para perseguição criminal em detrimento das garantias, liberdades e direitos fundamentais. O estudo enfrentará também a idéia da negação do princípio do Estado democrático de direito a partir da admissibilidade da perseguição criminal futura (medidas de prevenção avançada) que podem colocar em risco a manutenção de garantias fundamentais efetivas.
\end{abstract}

PALAVRAS-CHAVE: Processo Penal Democrático. Direitos Fundamentais. Perseguição Criminal.

\section{ABSTRACT}

This article focus on the question of the human rights affirmation under the perspective of liberty, security and justice through the construction of a Democratic Criminal Procedure. In view of the necessary concern on the law universe as the reality of the uncertain society of the negative phenomenon, related with authority or war models for criminal law in contrast with the garantism model. The discussion faces the problematic question of the rebuilding of criminal law of the Author, which aims the criminal

Doutor em Direito pela Universidade Católica Portuguesa - Faculdade de Direito. Diretor do ICPOL - Centro de Investigação. Professor do ISCPSI e da UAL - Lisboa. 
prosecution over the guarantees, liberty and fundamental rights. The study will analyze the negation of the democratic state of law from the admissibility of future criminal persecution (advanced prevention measures) that can put in risk the maintenance of effective fundamental guarantees.

KEYWORDS: Democratic Criminal Procedure. Fundamental Rights. Criminal Persecution.

\section{Enquadramento do tema no quadro das ciências criminais}

O tema que nos convidaram para tratar convoca vários pensares que se interligam e se interrelacionam no quadro das ciências criminais, sendo que nos prenderemos mais às questões das ciências jurídica e policiais como fundamento da afirmação dos direitos humanos em tempos de mutabilidade social. Este tema, próprio de uma realidade intersubjectiva comunicativa da ciência da tardo-modernidade, entronca em um olhar matemático-jurídico e teorético que temos, desde há alguns anos, vindo a $\operatorname{tratar}^{2}$ a trilogia do espaço penal europeu liberdade, segurança e justiça. É um encontro epistemológico e axiológico que o Direito não pode ignorar e que as ciências correlacionadas têm de assumir como seu objeto de estudo, de investigação e desenvolvimento. É um desiderato que o grupo das ciências criminais da PUC-RS agarrou e assumiu como caminho científico universitário, cuja valoração académica e científica ultrapassa a União Federativa do Brasil, fatualidade que nos merece todo apreço e uma congratulação por tão grande sucesso.

Mas este tema impõe uma visão global e profunda de outros subtemas a ele conexos e umbilicalmente ligados. Hoje, se me pedissem para reformular o tema desta conferência, optaria por colocar a Liberdade, Justiça e Segurança em um Processo Penal Democrático. É esta a linha que vou seguir e que, sem me escapulir à responsabilidade de abordar a tendência europeia e americana de securitização e policialização do processo penal - da justiça criminal -, procuro provocar as mentes presentes para os perigos constantes de um abrir da caixa de Pandora sem a certeza de que algum dia a possamos fechar, assim como relembrar que os momentos de liberdade e de efetividade de direitos fundamentais pessoais, vividos por nós, são fruto de um legado que os nossos antepassados nos deixaram e nos impõem que o defendamos, sob pena da dor e do sofrimento passado serem um vácuo inconsequente da nossa história.

A trilogia processo penal, segurança e liberdade inculca em nós a obrigação de trazer à discussão da plateia os fundamentos, os fins e os limites de cada axioma dentro do espírito de um Estado democrático de direito face à crise económica mundial, emergente de uma crise de valores e da crise de uma ética jus normativa, identificativa da vivência humana segundo axiomas que devem considerar o ser humano como o centro de toda a discus-

2 GUEDES VALENTE, Manuel Monteiro. Do mandado de detenção europeu. Coimbra: Almedina, 2006. 
são científica, capaz de germinar a crise da Constituição (melhor, a crise da interpretação da Constituição), a crise das instituições e a crise de identidade filosófico-jurídico-política.

É um desafio que vos coloco e me coloco todos os dias. O sábio não é aquele que fundamentaliza as posições, ou aquele que em prol da defesa inatacável do coletivo e da economia cede à ideia mais ténue e simples, ou aquele que se deixa embrenhar na lógica da eficácia. Mas antes aquele que procura e estuda a causa, analisa e aprofunda o fundamento, reafirma as barreiras inultrapassáveis e inabaláveis da Constituição e congloba e harmoniza os fins do indivíduo com os do Estado para que se construa um espaço jurídico de liberdade adequado a gerar um espaço de segurança, assente na justiça como baluarte da democracia.

Como sabem, temos defendido que o Direito processual penal é o Direito por excelência dos inocentes ${ }^{3}$ e, em simultâneo, é instrumento/meio jurídico de liberdade e de segurança - cognitiva, física, histórica e jurídica. Este pensamento é um desafio diário e coloca-se, hoje mais do que nunca, ao poder político-legislativo democrático e ao seu substrato de sustentabilidade - povo -, porque o Direito tem de ser cada vez mais a expressão de dois axiomas constitucionais: a vontade do povo e a dignidade da pessoa humana.

Mas este pensamento não pode esquecer que o processo penal está ao serviço da Justiça e da Liberdade dos cidadãos, e o seu funcionamento e o resultado da sua atividade em concreto geram a Segurança - a paz jurídica e social - que aspiramos. Convocamos, por ser essencial à nossa exposição, a tetralogia teleológica do Direito processual penal: realização da justiça [material com o respeito pela formalidade legal processual inscrita na Constituição e no Código de processo penal], descoberta da verdade material (não real), prática, processual e judicialmente válida [afastamo-nos das teses assentes unicamente na ideia de uma verdade formal], defesa e garantia dos direitos e liberdades fundamentais de todos os cidadãos [vítima direta e vítimas indiretas, indiciado, ou seja, como escrevera e dissera Günthers, "de todos os cidadãos"], e restabelecimento da paz jurídica e da paz social [quando a justiça criminal não a promove, o elemento gravitacional tempo repõe essa paz essencial à continuidade da vida em comunidade]. Claro é que nem sempre conseguimos promover na plenitude todas as finalidades do processo penal, cuja prossecução implica a vivência do princípio da concordância prática de modo a que possa aprofundar e harmonizar o melhor de cada uma das finalidades sem que alguma seja niilificada.

Há barreiras intransponíveis e que o Estado, em toda a sua dimensão, não pode alguma vez ceder com a ideia de que acima de tudo está a realização da justiça e a descoberta da verdade como forma de materializar a paz jurídica e social. A barreira intransponível dos direitos e liberdades fundamentais pessoais não pode cair sob pena de negarmos a legitimidade de punir do Estado. A trilogia do nosso tema tem como medula o axioma de que o Direito processual penal é o sismógrafo ou espelho da realidade constitucional (Roxin), ou sintoma do espírito político-constitucional de um ordenamento jurídico (Rudolphi) ou Direito constitucional aplicado (Henkel). O Direito processual penal está, genética e umbilicalmente, ligado aos direitos e liberdades fundamentais pessoais e à sua efetiva tutela.

3 GUEDES VALENTE, Manuel Monteiro. Escutas telefónicas. Da excepcionalidade à vulgaridade. Coimbra: Almedina, 2004 e 2008. p. 31. 
Desta forma estamos a fazer uma viagem capaz de nos ajudar a entender que a trilogia - processo penal, segurança e liberdade - é muito ampla e profunda, cuja resistência societária aos ventos da famigerada eficácia total se deve defender com todas as forças e todos os argumentos. Impõe-se-nos, pensadores e cultores do Direito como realização da condição humana em sociedade, alertar a sociedade atual para a enorme incerteza ou mutabilidade dos fenómenos positivos e dos fenómenos negativos.

Os fenómenos negativos redobram a nossa preocupação por influenciarem as decisões político-legislativas e por fomentarem a leveza de implementação de modelos pró-securitários, modelos securitários, modelos justicialistas, modelos autoritários, modelos totalitários ou de segurança nacional e modelos bélicos do Direito penal material e processual.

A defesa da implementação destes modelos, em detrimento do modelo garantista ou, do que defendemos, modelo do ser humano, assenta sempre numa ideologia de defesa do coletivo em detrimento do indivíduo, na defesa do Direito positivo em detrimento do Direito material, na defesa da segurança em detrimento da liberdade.

Esta trilogia - processo penal, segurança e liberdade -, disposta sistematicamente desorganizada segundo a nossa posição científica, é, por um lado, uma provocação uma vez que quem conhece o nosso pensamento sabe que a nossa construção matemática difere desta ordem sistemática - ou seja, deve ser liberdade, processo penal e segurança - e, por outro, demonstrativa da realidade atual da construção sistémica e matemática do espaço penal europeu: pró-securitário e, na linha crítica de Hassemer à funcionalização do Direito penal, assente na ideia de que o Direito penal material e processual está a transformar-se em instrumento de segurança. ${ }^{4}$

Preocupação que acompanhamos e que criticamos por se olvidar a história (a recente história da humanidade). É uma construção assente no teorema filosófico-político de que a segurança é a primeira das liberdades, contrariando a construção kantiana do nosso pensamento: a liberdade como o valor mais elevado da justiça.

Assumimos este desiderato kantiano e reconstruímos um novo teorema jus filosófico: a liberdade é a primeira das seguranças. ${ }^{5}$ Este teorema afasta a ideia de um Direito penal material e processual convertido em instrumento de segurança e repõe a segurança como bem jurídico fundamental garantia de todos os demais bens jurídicos tutelados pelo bloco da constitucionalidade. É a segurança que deve converter-se em instrumento da atividade jurídico-processual penal e não o contrário.

Impõe-se, desta forma e neste pequeno ponto, que façamos, em todo o processo de legiferação e de hermenêutica, uma análise aos fundamentos, aos limites e aos fins de cada um dos axiomas desta nossa palestra. O legislador e o intérprete/aplicador do Direito processual penal não pode ceder à máquina publicitária da eficácia plena, sob pena de detonarmos a eficiência dos fins e a espinha dorsal do Estado democrático de direito.

\footnotetext{
4 HASSEMER, Winfried. História das ideias penais na Alemanha do pós-guerra. Lisboa: AAFDL, 1995. p. 42-50; 63-82.

5 GUEDES VALENTE, Manuel Monteiro. Do ministério público e da polícia. Prevenção Criminal e Acção penal como Execução de uma Política Criminal do Ser Humano. Lisboa: UCE, 2013. p. 541.
} 
Este nosso pensamento conexiona-se com o pensamento de Bobbio sobre o Direito e o poder: $O$ poder sem direito é cego, e o direito sem poder é vazio. ${ }^{6}$ Como reforço desta ideia de limitação do poder soberano [político], Bobbio defende um "poder de fato, mas como um poder de direito, isto é, um poder também ele autorizado e regulado, como os poderes inferiores, por uma norma superior". ${ }^{7}$ Ou seja, consideramos, com esse autor do século XX e início do século XXI, que devemos passar do teorema - "movimento do poder ao direito, e do direito ao poder" do positivismo que marcou os momentos mais terríveis da história da humanidade - para o teorema inverso - movimento "do direito ao poder e do poder ao direito", ou seja, "não é a autoridade que faz a lei, mas 'a lei é que faz o rei', que confere autoridade à pessoa que dela foi investida e age em conformidade com a lei". ${ }^{8}$

Temos em cima da mesa um pensamento jus filosófico-político de legitimação e de força normativa limitativa do poder do Estado, em especial do poder de punir - materialidade e processualidade - que deve assentar em uma lógica de equilíbrio para que se realize o Direito segundo os primados da justiça material capaz de restaurar a paz jurídica e social e neutralizar todas as tentativas negativas de delação do Estado de direito material social democrático. Só, desta forma, podemos continuar afirmar que o Direito processual penal é o Direito por excelência dos inocentes por ter um lastro doutrinário e filosófico de uma "justiça-ordem" que "retoma e ilumina a ideia de justiça-lei e a ideia de justiça-igualdade". ${ }^{9}$

A segurança é instaurada (restaurada e conservada) por meio do exercício da liberdade, como valor do indivíduo face à sociedade de que é membro (local ou global), e por meio da promulgação de leis em geral e em especial da legislação processual penal construtiva de uma justiça que se afirma como "um fim desejável por parte de quem estabelece o ponto de vista da boa sociedade (iustitia fundamentum regnorum)", e de uma liberdade, como "fim desejável por parte de quem se coloca do ponto de vista do indivíduo". ${ }^{10}$

\section{A trilogia face aos fenómenos de construção do (direito) sistema integral penal do inimigo}

A sistemática do nosso tema é uma provocação às teorias regressivas de uma estruturação político-jurídica do Estado, assente na «coisificação» do ser Humano. O debate em torno da reedificação do Direito penal de autor, cujo expoente se afirma na per-

6 BOBBIO, Norberto. Teoria geral da política. A filosofia política e as lições dos clássicos. 20. reimpr. Tradução do Teoria Generale Della Politica de Daniela Beccaccia Versiani. Rio de Janeiro: Elsevier, 2000. p. 240.

7 BOBBIO, Norberto. Teoria geral da política. A filosofia política e as lições dos clássicos..., p. 239.

8 BOBBIO, Norberto. Teoria geral da política. A filosofia política e as lições dos clássicos..., p. 248.

9 BOBBIO, Norberto. Teoria geral da política. A filosofia política e as lições dos clássicos..., p. 319.

10 BOBBIO, Norberto. Teoria geral da política. A filosofia política e as lições dos clássicos..., p. 319. 
seguição criminal - em que os axiomas primazes são a perigosidade e a segurança -, assume preponderância a par da defesa de uma detração das garantias, das liberdades e dos direitos fundamentais processuais constitucionalizados. Este "novo" debate, preso à teoria securitária e justicialista do sistema jurídico, olvida a teleologia do Direito processual penal do Estado republicano democrático.

Este debate, iniciado com a prelação de Günther Jakobs em 1986 e desenvolvida em 1999, ${ }^{11}$ cujos seguidores podemos destacar Miguel Polaïno-Orts ${ }^{12}$ com uma tese de doutoramento direccionada a fundamentar um Direito Penal do Inimigo, deve ser sério e deve apresentar toda a argumentação histórico-filosófica-jurídica e política limitativa da abertura a uma porta que dificilmente será fechada nas próximas décadas. Devemos, desde logo, avocar o princípio da função limitativa do poder de punir por força da lei penal e recolocar aos fatos históricos que marcam o nosso ADN e nos dão a genética humanista e garantista, que não pode confundir-se com impunidade, impunibilidade e inimputabilidade.

A discussão em torno do estado natureza e do estado legal, que tem desencadeado vários estudos a favor da existência de seres humanos que por razões de periculosidade e de segurança coletiva não são dignos de tutela garantista penal material e processual, cujas condutas negativas dignas de tutela penal devem ser imprescritiveis, cujas garantias de defesa devem ser inócuas ou inexistentes [como se regressássemos ao tempo mais negro do modelo inquisitório], com a admissibilidade da privação da liberdade sem conhecimento dos fatos que são imputados ou por mera e indelével suspeita da prática de um crime do catálogo, e com a negação da pessoa como pessoa, (essa discussão) tem de ser reposta com clarividência e com a serenidade que os tempos nos impõe.

Os tempos líquidos [Bauman] e da sociedade do risco [Beck], ou a designada por nós sociedade internético-personocêntrica, impõem a avocação do princípio dos sábios antepassados: o princípio do equilíbrio e da afirmação do ser humano como ser frágil e pecador. A legiferação "à flor da pele" e em cima do joelho tem demonstrado como nos autonegamos e nos autodestruímos e negamos o legado dos nossos antepassados: direitos e liberdades fundamentais pessoais, que devem orientar o processo penal - legitimando-o, limitando-o e dando-lhe o fundo teleológico -, a segurança - fundamentada e limitada como necessidade/valor individual e colectivo, estado conceptual do ser humano e de Estado, sentimento real e cognitivo (ou psicológico-cognitivo), e, por fim, instrumento/meio/atividade e fim da vivência harmoniosa em comunidade ${ }^{13}$ - e a liberdade - valor supremo da justiça que é a virtude da concórdia (omonoia). ${ }^{14}$

\footnotetext{
11 Veja-se JAKOBS, Günther. Derecho penal del enemigo. Tradução de Manuel Cancio Meliá. 2. ed. Madrid: Thomson-Civitas, 2003.

12 Aconselhamos a leitura da sua tese de doutoramento: POLAÏNO-ORTS: Miguel. El derecho penal del enemigo. Editorial Mediterranea, 2006.

13 GUEDES VALENTE, Manuel Monteiro. Segurança. Um tópico jurídico em reconstrução. Lisboa: Âncora Editora, 2013. p. 133.

14 BOBBIO, Norberto. Teoria geral da política. A filosofia política e as lições dos clássicos. 20. reimpr. Tradução do Teoria Generale Della Politica de Daniela Beccaccia Versiani. Rio de Janeiro: Elsevier, 2000. p. 319.
} 
A teorização do direito penal do inimigo tem como base as políticas criminais pró-securitárias e securitárias seguidas pela União Europeia e pelos Estados-membros com a implementação das decisões quadro e com a transposição das directivas comunitárias em matéria de Direito penal desde o Tratado de Maastricht, ${ }^{15}$ alterado e mantido pelo Tratado de Amesterdão, ${ }^{16}$ integrados pelo Tratado de Funcionamento da União Europeia (Tratado de Lisboa). ${ }^{17}$

A aceleração da política criminal europeia de restrição de direitos e liberdades fundamentais pessoais e de delação ou negação de garantias efetivas no quadro do Direito penal material e processual ganha fôlego (ou seja, amplia-se) com o 11 de setembro de 2001, e promove um efeito paradoxo de que nos fala Charadeau: a transmissão direta dos atentados faz-nos acreditar que "o visível do mundo é apenas um invisível, intocável, construído como visível pelo efeito conjunto de uma colocação em espectáculo e da projeção da nossa memória sobre o espectáculo"; assistimos e vivemos as "vítimas", vemos "os cadáveres, falam-nos dos mortos, mas nunca ninguém viu a morte", e como "seres humanos, não temos nenhum indício dela (a não ser, talvez, Lázaro)", o que nada impede que "construamos o seu espectáculo como um fantasma necessário, demanda insaciável da verdade, talvez porque esse espectáculo remete sempre para a nossa própria morte". ${ }^{18}$

É essa busca insaciável da verdade impossível que tem dirigido os trabalhos legislativos supranacionais, teorizados sob o primado da periculosidade e da segurança, com a criação de um catálogo de crimes hediondos - terrorismo, tráfico de armas, tráfico de seres humanos, tráfico de órgãos, tráfico de droga, branqueamento, corrupção - e um Direito processual penal especial para a sua perseguição criminal.

O espectáculo molda o pensar do povo e este, na esperança de uma segurança física real (que não passa de cognitiva), cede e aplaude as novas restrições sempre com a ideia de que o presídio e a morte são para os outros. Veja-se a admissibilidade da desjurisdicionalização da cooperação jurídica no espaço penal europeu: ocupa o primeiro patamar a cooperação policial; em segundo lugar, a cooperação judiciária; e, quando estes não se afiguram capazes de promover o desejado espaço de liberdade, segurança e justiça, admite-se a cooperação jurídica na essência material e processual (harmonização do Direito penal material e processual, base de toda e qualquer confiança mútua entre os operadores judiciários de cada Estado-membro ou Estado-parte).

A mesma crítica se direcciona à onda do Direito penal preventivo com a antecipação da prevenção da lesão dos bens jurídicos ou da colocação em lesão de bens jurídicos dignos da tutela penal, assim como a admissibilidade de recurso de investigação ante-

15 Cfr. artigos K.1 a K.14 (K.1 a K.6) do Tratado de Maastrich.

16 Cfr. artigos $29^{\circ}$ a $42^{\circ}\left(29^{\circ}\right.$ a $\left.34^{\circ}\right)$ do TUE.

17 Cfr. artigos $67^{\circ}$ a $80^{\circ}$ e $82^{\circ}$ a $89^{\circ}$ do TFUE.

18 CHARADEAU, Patrick. Informação, emoção e imaginários. A propósito do 11 de Setembro de 2001. Daniel Dayan. O Terror Espectáculo. Terrorismo e Televisão. Lisboa: Edições 70, 2009. p. 84-85. 
cipada ou de campo avançado no quadro processual penal. ${ }^{19}$ É o regresso à ideia de que existem delinquentes pré-estabelecidos e pré-identificados, que devem ser vigiados e as suas condutas investigadas de modo que se evite um crime no futuro e se possa, por antecipação, obter indícios probatórios ou provas para serem utilizados no processo logo que ocorra a conduta negativa lesiva de bens jurídicos tutelados pelo Direito penal. Consideramos que podemos estar perante a violação do princípio do risco permitido e do princípio da adequação social da conduta, por essas condutas entroncarem na teoria do risco permitido pela sociedade e, em muitas situações, se enquadrarem no âmbito da adequação social da conduta e nunca preencherem qualquer elemento objectivo de lesão de um bem jurídico identificado em concreto, digno de tutela penal.

A política criminal securitária e quase bélica, que nos últimos anos tomou conta do espectro jurídico-político europeu ${ }^{20}$ e mundial - veja-se a Convenção das Nações Unidas da Contra a Criminalidade Organizada Transnacional, conhecida por Convenção de Palermo, e os respectivos protocolos adicionais -, assenta no fantasma do terrorismo e na construção de um sistema jurídico ao serviço da segurança, sacralizada como único valor jurídico digno de reforço legiferante e de tutela jurídico-criminal.

Este desenvolvimento regressivo do Direito e das demais ciências criminais, defensor de um endurecimento da ação do Estado na "luta", "combate" e "guerra" ao crime organizado, assume uma amplitude que coloca em causa a estrutura acusatória do processo penal - inscrita como princípio constitucional - e a dimensão da liberdade como princípio reitor do Direito processual penal, e atribui a primazia à segurança.

Como já se devem ter apercebido, este movimento positivista de negação da qualidade de pessoa humana, dotada de direitos e de deveres, não assenta na essência valor teleológico do Direito penal: prevenção e repressão. Assenta em um discurso de «guerra», de «luta» e de "combate», fazendo regressar as nomenclaturas próprias da estratégia militar em detrimento da nomenclatura do Direito. Mas, como havíamos escrito ${ }^{21}$ (Guedes Valente, 2010), se reclamamos o discurso militar, negamos o Direito e, neste caso concreto, negamos o Direito penal material e processual e, por conseguinte, negamos a liberdade como o mais elevado valor da justiça.

O 11 de setembro de 2001, o 11 de março 2004 e o 7 de julho de 2005 são o toque de alvorada de um Direito penal do inimigo, que também é um Direito processual penal do inimigo e um Direito penitenciário do inimigo. Podemos, assim, falar de um sistema integral penal do inimigo que tem como barreira intransponível a política criminal humanista e garantista.

Esta aceção agrava-se com o fenómeno da administrativização do Direito penal material, processual e penitenciário e com a ampliação da intervenção do Direito penal para

19 GUEDES VALENTE, Manuel Monteiro. Do ministério público e da polícia. Prevenção criminal e acção penal como execução de uma política criminal do ser humano. Lisboa: UCE, 2013. p. 55-57 e 316-319.

20 Vejam-se o art. $29^{\circ}$ e ss. do TUE e os atuais arts. $67^{\circ}$ e $82^{\circ}$ e ss. do TFUE.

21 GUEDES VALENTE, Manuel Monteiro. Processo penal. Coimbra: Almedina, 2010. 
tutelar bens jurídicos sem dignidade penal $[v . g$., criminalização da luta entre animais com a ideia de Direito preventivo do perigo ou da periculosidade $]^{22}$ e com a consequente redução [quantas vezes delação] das garantias efetivas judiciárias e jurisdicionais. Por um lado, alarga-se o espaço securativista - por meio do fenómeno da policialização dos procedimentos processuais penais - e, por outro, complementa-se este ajuste em prol de uma maior segurança cognitiva com a diminuição de garantias processuais penais, ou seja, implementa-se um modelo justicialista.

Esta redução de garantias processuais penais ganha amplitude e profundidade no quadro dos meios de obtenção de prova, em especial a abertura aos meios de maior danosidade social: buscas domiciliárias nocturnas, apreensão de correspondência, escutas telefónicas, registo de voz (off) e imagem, agente infiltrado, controlo e aquisição de dados informáticos, admissibilidade de testemunhos de ouvir-dizer em casos específicos de terrorismo, admissibilidade de detenção e perseguição total sem comunicação do fundamento legal e respetiva libertação sem informação das razões da ação policial, admissibilidade de meios atípicos não contrários aos princípios positivados no processo penal [medidas de polícia no quadro da segurança interna convertem-se em imediatos meios de prova sem apreciação e validação judicial], admissibilidade da teoria da proibição relativa de meios proibidos de prova, e, como alguns Autores defendem, admissibilidade de prova proibida como único meio adequado de prova da prática daquele crime [B. Schünneman - a questão é de valoração da prova (campo processual) e não uma questão de ilicitude (de validade) da produção de prova (campo material)].

No plano do Direito penitenciário, a simples admissibilidade de restrição de direitos dos reclusos por decisão administrativa e política com fundamento em um procedimento disciplinar sem garantia jurisdicional (como o direito de recurso das decisões judiciárias). No plano do Direito penal material, podemos alertar para o perigo de violação do princípio da prescritividade da conduta negativa punida pela legislação penal legitima, válida, vigente e efetiva, derrubando um primado da finalidade do restabelecimento da paz jurídica e social, negando ao tempo a força gravitacional de reposição da justiça-ordem de que nos fala Bobbio, e negando a concretização da prevenção na sua magnitude dos três elementos energéticos: vítima, indiciado e comunidade..$^{23}$

Podemos trazer à colação a técnica político-judiciária de prorrogação de julgamentos para manter um cidadão preso ad aeternum em vez de se optar pela conexão de processos ou de se respeitar a extensibilidade dos efeitos do caso julgado parcial ao caso julgado total, tendo como base a defesa de que todos os fatos criminosos pertencem ao

22 Quanto a este assunto e uma crítica à tese de Fernanda Palma, que defende o Direito penal preventivo do perigo como forma de tutela preventiva de bens jurídicos. GUEDES VALENTE, Manuel Monteiro. Do ministério público e da polícia. Prevenção criminal e acção penal como execução de uma política criminal do ser humano. Lisboa: UCE, 2013. p. 55-57.

23 GUEDES VALENTE, Manuel Monteiro. Do ministério público e da polícia. Prevenção criminal e acção penal como execução de uma política criminal do ser humano. Lisboa: UCE., 2013. p. 311. 
mesmo pedaço da vida. ${ }^{24}$ Esta prorrogação judicativa destrona a tutela efetiva dos direitos, liberdades e garantias fundamentais processuais penais dos arguidos. Podemos, ainda, falar do recurso a medidas de segurança interna desenvolvidas pela polícia, de natureza administrativa, e a fundamentação do recurso com base em estados de perigosidade abstractos e a sua convolação em meios de prova processual penal sem a tutela jurisdicional prévia e, quantas vezes, subsequente e imediata.

Podemos, nestas paragens, avocar os processos administrativos de investigação no quadro da prevenção e repressão da criminalidade económico-financeira e tributária - fraude tributária, lavagem de dinheiro e corrupção - que servem de base para uma recolha de prova dessas infrações sem autorização judicial e, logo que obtida e "certos" de que existe um crime, revalida-se a prova obtida por uma nova reprodução da prova (nova recolha), agora já com autorização judicial. Esta atitude de procedimento processual - que parece poder aferir-se do normativo positivado - é contrária ao princípio democrático e ao princípio da lealdade, regentes da estrutura acusatória do processo.

\section{A negação do princípio do Estado de direito democrático por meio da admissibilidade das investigações de campo avançado (Vorfeld) e da perseguição criminal (futura) de crimes (Vorsoge für die Verfolgung von Straftaten)}

A teoria da periculosidade e da segurança como único bem vital único ou primaz da ação do Estado tem aberto a porta ao discurso de novos paradigmas de prevenção policial e judiciária, assim como traz a discussão sobre essas medidas preventivas e a respectiva admissão poder violar o princípio do Estado de direito democrático. Essas medidas entroncam em dois tempos de intervenção pré-processual e processual penal e detêm fundamentos, limites e fins distintos. Ora vejamos.

O primeiro plano temporal prende-se com a função de garantia de segurança interna, que absorve a defesa e garantia da legalidade democrática, ${ }^{25}$ e contempla as designadas medidas de polícia puras ou originárias, que podem ser classificadas de medidas de prevenção (criminal) avançada, designadas pela doutrina e jurisprudência alemã de medidas de prevenção de "Vorfeld (campo avançado)". Quando não existe o mínimo perigo, essas medidas designam-se de providências de "combate preventivo do crime (vorbeugende Bekämpfung von Straftaten)", e, quando existe perigo abstracto e concreto de uma possibilidade de ulterior prática de crimes, designam-se de providências "para perseguição criminal (futura) de crimes (Vorsoge für die Verfolgung von Straftaten)" ${ }^{26}$

24 GUEDES VALENTE, Manuel Monteiro. Do Mandado de Detenção europeu. Coimbra: Almedina, 2006. p. 247272; GUEDES VALENTE, Manuel Monteiro. Do ministério público e da polícia. Prevenção criminal e acção penal como execução de uma política criminal do ser humano. Lisboa: UCE, 2013. p. 509-522.

25 Cfr. em Portugal o $\mathrm{n}^{\circ} 1$ do art. $272^{\circ}$ do CRP.

26 Cfr. a linha do Tribunal Constitucional alemão, Costa Andrade, 2009, p. 131. As providências de "combate preventivo do crime (vorbeugende Bekämpfung von Straftaten)" tem como escopo a prevenção e o afastamento de 
As medidas de prevenção (criminal) avançada têm eco nas legislações de segurança interna [Portugal] ou segurança nacional [Inglaterra], são ordenadas por uma Autoridade de Polícia ${ }^{27}$ e executadas por agentes de polícia que lhes estão subordinados na função de comando e dependência hierárquica. Estas medidas podem ser medidas (gerais) de polícia $^{28}$ - v. g., identificação de pessoas, suspeitas, interdição temporária de acesso e circulação, evacuação ou abandono temporários, remoção de objectos, veículos ou outros obstáculos - ou medidas especiais de polícia ${ }^{29}-$ p. e., realização de revistas e buscas para detectar armas, substâncias ou engenhos explosivos; apreensão temporária de armas, munições, explosivos e substâncias ou objectos proibidos; realização de acções de fiscalização em estabelecimentos e outros locais públicos ou abertos ao público; acções de vistoria ou instalação de equipamentos de segurança; encerramento temporário de paióis; revogação ou suspensão de autorizações aos titulares dos paióis, depósitos ou fábricas de armas ou explosivos; encerramento temporário de estabelecimento de venda de armas, cessação da actividade de empresas, grupos, organizações ou associações dedicadas ao terrorismo ou à criminalidade violenta ou altamente organizada; inibição de comunicação por isolamento electromagnético ou barramento de comunicações.

Mas nem todas as medidas especiais de polícia - admiravelmente não as que afetam mais os direitos, liberdades e garantias fundamentais do cidadão, mas as que se prendem com o comércio quotidiano de uso de explosivos e armas - carecem da prévia autorização do JIC quando, em especial, a urgência e o periculum in mora justificarem a ação policial por determinação da Autoridade de Polícia. ${ }^{30}$

Estas medidas têm um fim específico: "proteger a vida e a integridade das pessoas, a paz pública e ordem democrática, designadamente contra o terrorismo, a criminalidade violenta ou altamente organizada, a sabotagem e a espionagem, a prevenir e reagir a acidentes graves ou catástrofes, a defender o ambiente e a preservar a saúde pública”, ex vi $\mathrm{n}^{\circ} 3$ do art. $1^{\circ}$ da LSI.

\footnotetext{
"perigos (crimes) possíveis antes de se atingir o limiar do perigo concreto", conquanto as providências "para perseguição criminal (futura) de crimes (Vorsoge für die Verfolgung von Straftaten)" se destinam a recolher e tratar provas para uma ulterior perseguição criminal e punibilidade de crimes que ainda não foram praticados, mas que se revela possível e provável, "num futuro incerto", a sua prática. Estamos a chegar ao Minority Report. Quanto a este assunto: GUEDES VALENTE, Manuel Monteiro. Do ministério público e da polícia. Prevenção criminal e acção penal como execução de uma política criminal do ser humano. Lisboa: UCE, 2013. p. 306-311.

${ }^{27}$ Cfr. o art. $26^{\circ}$ conjugado com o $\mathrm{n}^{\circ} 1$ do $32^{\circ}$ da Lei de Segurança Interna [LSI]. Os agentes de polícia podem executar as medidas gerais de polícia - art. $28^{\circ}$ - e as medidas especiais de polícia das alíneas (a) e (b) do art. $29^{\circ}$ da LSI sem autorização ou ordem da Autoridade de Polícia, estando obrigados a comunicar imediata à Autoridade de Polícia de que dependem hierarquicamente, conforme $\mathrm{n}^{\circ} 2$ do art. $32^{\circ}$ da LSI.

28 Cfr. art. $28^{\circ}$ da LSI. Quanto às medidas de polícia que podem consistir em actos jurídicos e em operações materiais e que revestem a natureza de medidas de segurança administrativas. RAPOSO, João. Direito policial - I. Coimbra: Almedina, 2006. p. 23-27.

29 Cfr. art. 29ํㅡㅁ LSI.

30 Cfr. no 3 do art. $32^{\circ}$ da LSI.
} 
Face a este escopo de segurança interna de prevenção de crimes puníveis com pena de prisão, no seu máximo, superior a cinco anos, ${ }^{31}$ levanta-se a questão da valoração das provas obtidas com a intervenção da Polícia no quadro da LSI. O problema agrava-se, na linha de pensamento de Costa Andrade, ${ }^{32}$ quando não há provas ou indícios concretos da prática de crime e só existem elementos probatórios da probabilidade de uma futura prática de crime que são recolhidos pela Polícia para uso futuro: pré-selecção de presumíveis futuros autores de crimes com base em pré-indícios probatórios.

É neste plano funcional de prevenção que devem intervir as medidas de prevenção (criminal) avançada, designadas pela doutrina e jurisprudência alemã de medidas de prevenção de "Vorfeld (campo avançado)", que, quando não existe o mínimo perigo, se designam de providências de "combate preventivo do crime (vorbeugende Bekämpfung von Straftaten)", que podem ter expressão nas medidas gerais e especiais de polícia, previstas nas legislações designadas de Leis de Segurança Interna ou de Segurança Nacional, ou mesmo em legislação avulsa - v. g., a revista preventiva obrigatória para membros de "grupos organizados de adeptos" a efetuar pelas forças de segurança à entrada do recinto desportivo, ${ }^{33}$ de forma a possibilitar a realização dos mesmos em segurança.

É nesta função que se enquadram as providências "para perseguição criminal (futura) de crimes (Vorsoge für die Verfolgung von Straftaten)". ${ }^{34}$ Esta função preventiva gera o perigo de colocar em causa a manutenção de garantias fundamentais efetivas. Temos consciência de que existe criminalidade organizada transnacional, cuja obtenção da prova é objetivamente muito difícil e a descoberta da verdade comprometida, mas parece-nos que é elevado o perigo, pela possível elevada danosidade social, a defesa de admissibilidade destas providências cautelares policiais e, muito menos, a admissibilidade da valoração de provas obtidas no âmbito destas providências para perseguição futura dos agentes desses crimes. Estas providências, que assentam na urgência e na periculosidade da conduta humana, entroncam na ideia de afastamento da tutela jurisdicional e, em simultâneo, de promoção da administrativização (policialização) das medidas preventivas convoladas em puros meios de obtenção de prova.

Esta admissibilidade, que não perfilhamos, implica uma selecção dos presumíveis agentes desses crimes - presunção de criminoso antes de o ser - e uma acção de vigilância de recolha de prova sem controlo judiciário e jurisdicional e uma total policialização da produção de prova com base no princípio da periculosidade futura de conduta delituosa. Como afirma Claus Roxin, o recurso à tecnologia para prevenção de atos lesivos da segurança

31 Cfr. alíneas (i), (j), (l) e (m) do art. 1º do CPP português.

32 ANDRADE, Manuel da Costa. Bruscamente no Verão Passado. A Reforma do Código de Processo Penal. Observações críticas sobre uma lei que podia e devia ser diferente. Coimbra: Coimbra Editora, 2009. p. 132.

33 Prevista no nos $3^{\circ}$ e $4^{\circ}$ do art. 25ํㅡㄹ da Lei $n^{\circ} 39 / 2009$, de 30 de julho, que aprova o regime jurídico do combate à violência, ao racismo, à xenofobia e à intolerância nos espectáculos desportivos.

34 ANDRADE, Manuel da Costa. Bruscamente no Verão Passado. A Reforma do Código de Processo Penal. Observações críticas sobre uma lei que podia e devia ser diferente. Coimbra: Coimbra Editora, 2009. p. 131. 
interna e a utilização da prova produzida por medidas de prevenção exige uma minuciosa e fundada regulamentação no "respeito pelos direitos de personalidade individuais, se quisermos evitar comportamentos de um Estado de polícia". ${ }^{35}$

Desde logo, assistimos à violação do princípio da presunção de inocência por admissibilidade do princípio da presunção de predisposição do ser humano $X$ ou $Y$ para a prática de crimes futuros. Existe um retomar das teorias fisiológicas do criminoso [Lombroso], hereditárias [Garófalo] e sociais ou sociológicas [Ferri]. Regressa a topologia de intervenção segundo as presunções de seres humanos - cives - e de (não) seres humanos - non cives.

O regresso ao sistema político-jurídico de Estado segregador com fundamento de que a Segurança é tudo (e é nada), olvida a história recente da humanidade. Negar que todos somos seres humanos - pessoas dotadas de dignidade humana -, inseridos em uma sociedade humana, é negar o ser humano e o valor da vida e da liberdade de cada um de nós e do próprio Estado, é convertê-lo em um não-Estado, ou em uma autoridade corrompida e ilegítima. Impõe-se contenção e moderação nas metodologias e medidas investigatórias que se desejam implementar para neutralizar o fantasma do terrorismo.

Como escrevemos, não olvidamos que vivemos em um mundo complexo, embrenhado em uma criminalidade especializada e altamente violenta, mas admitir um modelo de investigação criminal sem a existência de um crime é negar o substrato, a dimensão penal material e processual da investigação criminal. É negar o primado da acção penal constitucional. É negar a Constituição democrática. Esse discurso de admissibilidade de presunção de futuros delinquentes - como se vivêssemos em guerra de espionagem - é voltar a militarizar a justiça e a segurança (pública) com o fundamento da prevenção e repressão do crime se converter em "luta", "combate" e "guerra" contra a criminalidade organizada, como se não existisse o Estado de direito material social democrático.

Mas e face às tentativas de implementação de medidas legislativas processuais de prossecução de segurança, que se possam converter em automáticos meios de prova ou em futuros meios de prova, impõem-se que, neste deambular do século, criemos uma barreira doutrinal e filosófico-constitucional ao legislador ordinário e identifiquemos um leque de princípios regentes da mutabilidade da investigação criminal, para orientação teleológica quando (ou se) viermos a admitir a investigação criminal preventiva (de futuros) crimes:

- Princípio da reserva de Constituição na identificação do catálogo das tipologias criminais e dos meios restritivos de persecução criminal.

- Princípio da reserva de código penal e de código de processo penal.

35 ROXIN, Claus. Sobre o desenvolvimento do direito processual penal alemão. In: FERREIRA MONTE, Mário; CALHEIROS, Maria Clara; MONTEIRO, Fernando Conde; LOUREIRO, Flávia Noversa. (Coords.) Que futuro para o Direito Processual Penal? Simpósio em Homenagem a Jorge de Figueiredo Dias, por ocasião dos 20 anos do Código de Processo Penal Português. Tradução do alemão de Inês Godinho. Coimbra: Coimbra Editora, 2009. p. 393. 
- Princípio do catálogo dos fenómenos criminais e dos instrumentos jurídico-processuais penais e policiais e princípio da proporcionalidade da intervenção penal material e processual. ${ }^{36}$

- Princípios da constitucionalidade e da legalidade: reserva absoluta de lei, precedência de lei e preferência de lei [afasta-se toda e qualquer teoria de atipicidade de meios probatórios neste quadro jurídico-criminal investigatório preventiva].

- Princípio da limitatividade de tipos legais de crime, de meios de obtenção de prova de elevada lesividade e de agentes ativos e passivos dos meios processuais a utilizar.

- Princípio odiosa sunt restringenda na interpretação das normas restritivas de direitos, liberdades e garantias processuais penais.

- Princípio da tutela efetiva jurisdicional [ab initio] e efetivo controlo judiciário dos meios a utilizar ao longo da investigação [preventiva e, posteriormente, persecutiva].

- Princípio da presunção de inocência e da comunicabilidade e posterior destruição do material produzido no âmbito das investigações preventivas (de futuro) de crimes.

- Princípio da suspeita objetiva do futuro agente do crime, ou seja, impõe-se uma suspeita não abstracta ou de animosidade pessoal ou ideológico-política-religiosa.

- Princípio da efetividade dos direitos, liberdades e garantias fundamentais pessoais de todos os cidadãos.

- Princípio da superioridade ética do Estado, em especial dos operadores judiciários em que à veracidade se afirme a lei, ao belo e estético a forma processual material e judicial e ao bem a justiça ou dever ser metapositivo.

- Princípio da dignidade da pessoa humana como a fronteira intransponível na perseguição preventiva e de campo avançado, que o Estado alguma vez pode violar sob pena de se deslegitimar.

\section{Considerações finais}

É tempo de terminar. A liberdade é o mais elevado valor da justiça, que tem de ser prosseguido no quadro da perseguição criminal por meio de um processo penal garantista e humanista, que deve ser concretizado por meio de uma melhor formação académica

36 Avoca-se, quanto ao respeito do princípio da proporcionalidade na intervenção penal e controlo das normas penais, o pensamento de Luciano Feldens (2012, p. 129-171), Cesare Beccaria (1998, p. 64-66, 72-75 e 84-85), Luigi Ferrajoli (2005, p. 392, 397-399, 749) e, quanto às medidas cautelares, Nereu Giacomolli (2013, p. 37-40). 
e científica dos operadores judiciários - magistrados, promotores públicos, ministério público, policiais - e uma formação assente na ideia de que a justiça criminal é aplicada por Homens, sobre Homens e com uma lei elaborada e aprovada por Homens.

Podemos, assim, resumir a nossa exposição - assente na trilogia liberdade (L), justiça $(\mathrm{J})$ e segurança $(\mathrm{S})$ - no seguinte teorema matemático:

$$
\mathrm{E} d d=\frac{\mathrm{D} p(m+p r+p e)}{+\mathrm{L}}=\mathrm{S}
$$

Afastamo-nos do teorema $S \approx$ Defesa coletivo $=S \approx E d s$, por não corresponder à construção de uma justiça da democracia ou de uma democracia assente na justiça e na liberdade. Ora vejamos:

$\mathrm{L} \approx \mathrm{D}[$ (epistemologia + axiologia $)+$ pensar cultural de um povo + pensar conceitual de ser humano + pensar conceitual de Estado]

$$
\mathrm{D} p \approx \mathrm{J}
$$

$\mathrm{S} \approx$ Exercício efetivo $\mathrm{dlgf}$

$\mathrm{S}=\mathrm{E} d d$

$\mathrm{E} d d \approx \mathrm{D} m \approx \mathrm{J} \approx$ Democracia

Democracia $\approx$ Justiça $\approx$ Democracia

Sendo:

Edd $=$ Estado de direito democrático

MsJ = Macrossistema Jurídico

$\mathrm{D} p=$ Direito penal

$\mathrm{D} m=$ Direito material

$m=$ material

$p r=$ processual

pe $=$ penitenciário

Eds $=$ Estado de direito securitário

dlgf $=$ direitos, liberdades e garantias fundamentais

A segurança tem de ser uma consequência, e nunca uma causa, da justiça processual penal e da liberdade, axiomas dotados de uma axiologia constitucional genética do ser humano. Desta feita, reforço o nosso pensamento, que nos acompanha desde há mais de vinte e três anos de estudo universitário e científico: a liberdade [de todos os cidadãos] é a primeira de todas as seguranças. 


\section{Bibliografia}

ANDRADE, Manuel da Costa. Bruscamente no verão passado. A reforma do Código de Processo Penal. Observações críticas sobre uma lei que podia e devia ser diferente. Coimbra: Coimbra Editora, 2009.

BECCARIA, Cesare. Dos delitos e das penas. 2. ed. Tradução do Dei Delitti e Delle Pene de José de Faria Costa. Lisboa: Fundação Calouste Gulbenkian, 1998.

BOBBIO, Norberto. Teoria geral da política. A filosofia política e as lições dos clássicos. 20. reimpr. Tradução do Teoria Generale Della Politica de Daniela Beccaccia Versiani. Rio de Janeiro: Elsevier, 2000.

CHARADEAU, Patrick. Informação, emoção e imaginários. A propósito do 11 de Setembro de 2001. Daniel Dayan. O Terror Espectáculo. Terrorismo e Televisão. Lisboa: Edições 70, 2009.

DIAS, Jorge de Figueiredo. Direito processual penal. Lições coligidas por Maria João Antunes. Coimbra: Texto Policopiado, 1988-9.

FELDENS, Luciano. Direitos fundamentais e direito penal - A Constituição Penal. 2. ed. revista e ampliada. Porto Alegre: Livraria do Advogado, 2012.

FERRAJOLI, Luigi. Derecho y razón. Teoría del garantismo penal. 7. ed. Tradução do italiano de Perfecto Andrés Ibáñez et al. Madrid: Trotta, 2005.

GIACOMOLLI, Nereu José. Prisão, liberdade e as cautelares alternativas ao cárcere. São Paulo: Marcial Pons, 2013.

GUEDES VALENTE, Manuel Monteiro. Escutas telefónicas. Da excepcionalidade à vulgaridade. Coimbra: Almedina, 2004 e 2008.

. Do mandado de detenção europeu. Coimbra: Almedina, 2006.

. Do ministério público e da polícia. Prevenção criminal e acção penal como execução de uma política criminal do ser humano. Lisboa: UCE, 2013.

. Segurança. Um tópico jurídico em reconstrução. Lisboa: Âncora Editora, 2013.

. Processo penal. Coimbra: Almedina, 2010.

HASSEMER, Winfried. História das ideias penais na Alemanha do pós-guerra. Lisboa: AAFDL, 1995.

JAKOBS, Günther. Derecho penal del enemigo. 2. ed. Tradução de Manuel Cancio Meliá. Madrid: Thomson-Civitas, 2003.

POLAÏNO-ORTS, Miguel. Derecho penal del enemigo. Barcelona: Bosch, 2009.

RAPOSO, João. Direito policial - I. Coimbra: Almedina, 2006.

ROXIN, Claus. Sobre o desenvolvimento do direito processual penal alemão. In: FERREIRA MONTE, Mário; CALHEIROS, Maria Clara; MONTEIRO, Fernando Conde; LOUREIRO, Flávia Noversa. Que futuro para o Direito Processual Penal? Simpósio em Homenagem a Jorge de Figueiredo Dias, por ocasião dos 20 anos do Código de Processo Penal Português e Tradução do alemão de Inês Godinho. Coimbra: Coimbra Editora, 2009. 